British Journal of Psychiatry (1987), 151, 557-564

\title{
Correspondence
}

Editor: Greg Wilkinson

Contents: A search for sub-clinical arteriosclerotic dementia/Review of Behavioural Psychotherapy/ Range of mental illness among the elderly in the community/Mania following head injury/Schizophreniform episode following measles infection/Electrodermal response as a monitor in ECT/Neuroleptic malignant syndrome or lithium neurotoxicity?/ Tuberous sclerosis and the autistic syndrome/Delusional parasitosis/Lucid intervals in catatonia: a neuropsychiatric snare for the unwary/Sub-cortical dementia and the EEG/'Barking mad'/Ofloxacininduced psychosis/Oxymethalone and aggression

\section{A Search for Sub-Clinical Arteriosclerotic Dementia}

SIR: McDonald \& Sudhaker (Journal, July 1987, 151, 134-135) state that "the high discordance between the pathological findings and the ante-mortem diagnosis of arteriosclerotic dementia is well known". Such discordance was not evident in my own cases from an American mental hospital (Birkett, 1972) in the days before $C T$ scans. The autopsy findings were predicted with considerable accuracy.

Proving or disproving the existence of arteriosclerotic dementia without infarcts is difficult. The closest we have so far come is probably in Corsellis's (1962) study. He found cerebral arteriosclerosis without infarcts to be significantly commoner in demented patients than in matched controls from the same hospital with functional psychosis.

Until such studies can be replicated it is probably best to follow Alzheimer (1894) and call the condition mental disorder based on arteriosclerosis ("Seelenstoerungen auf arteriosclerotischer Grundlage"), specifying the presence of dementia and the presence of proven infarcts.

\section{Copeland Drive}

Suffern, NY 10901

USA

\section{References}

AlzhEMmER, A. (1894) Die arteriosklerotische Atrophie des Gehirns. Jahresversammlung des Vereins der Deutschen Irrenaerzte zu Dresden, p. 809.
BIRKETT, D. P. (1972) The psychiatric differentiation of senility and arteriosclerosis. British Journal of Psychiatry, 120, 321-325.

Corsellis, J. A. N. (1962) Mental Illness and the Aging Brain. London: Oxford University Press.

\section{Review of Behavioural Psychotherapy}

SIR: Mackay (Journal, July 1987, 151, 136) implies that the behavioural interventions described in this book are applicable only to "simple phobias and obsessional disorders". He seems to have missed most of the book's content. Of its eleven detailed case histories with clinical management protocols, only two concern simple problems. The remaining nine case illustrations are of complex disabling difficulties, including severely handicapping agoraphobia, social skills deficits, sexual dysfunction, sexual deviation, eating disorder, irritable bowel syndrome, and stammering. Many of the patients whose behavioural treatments are detailed are among the most complex and difficult to be found in psychiatric practice. Mackay's suggestion that adding a cognitive approach enhances behavioural treatment flies in the face of most controlled evidence in the field of anxiety disorders (reviewed by Marks (1987), chapter 14).

Institute of Psychiatry

ISAAC MARKS

Denmark Hill

London SE5 8 AF

Reference

MArks, I. M. (1987) Fears, Phobias and Rituals. New York: Oxford University Press.

Range of Mental Illness Among the Elderly in the Community

SIR: I am perplexed as to why Copeland et al (Journal, June 1987, 150, 815-823) consider their elderly mental ill as divided into Caucasian, Mongoloid and Negroid "races". These are now abandoned terms in biological anthropology, and have no obvious relevance, either, to current (socio-political) use of the term 'race'. What did the interviewers mean by describing an individual as 'Negroid'? Most 